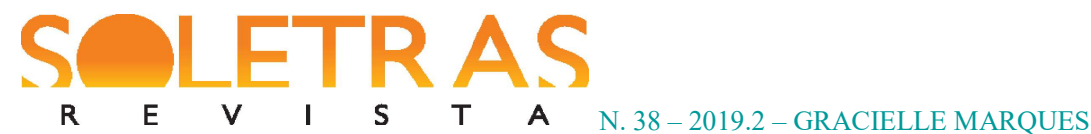

\title{
Poética do esquecimento: uma aproximação à microficção de María Rosa Lojo
}

\author{
Gracielle Marques ${ }^{1}$
}

\begin{abstract}
Resumo: O presente artigo se centra na análise de algumas microficções do livro Bosque de Ojos: microficciones y otros textos breves (2011), de María Rosa Lojo (1954 - Buenos Aires). Produzidas ao longo de mais de duas décadas de trabalho, as microficções lojianas formam um conjunto marcado pela hibridez genérica, reforçando o caráter multifacetado de seu projeto literário. Muitos dessas formas breves compartilham traços genéricos e temáticos que ressignificam o "entre-lugar" cultural enraizado em sua biografia pessoal e familiar, de maneira singular. A partir do conceito de "objeto perdido" de Suárez-Araúz (2010) e dos estudos críticos sobre a microficção de Noguerol Jiménez (2007),Zavala (2006), entre outros,esta análise objetivou estabelecer a relação entrea brevidade e a recriação da memória cindida, reflexo da diáspora galega. Como resultado da análise, em linhas gerais, é possível constatar que Lojo enriquece a dialética memória/esquecimento sob o ângulo dos objetos perdidos, expressão simbólica que funciona como matéria criativa para reinventar a identidade cultural, feita de lacunas.
\end{abstract}

Palavras-chave: Exílio. Literatura argentina contemporânea. Microficção. Objeto perdido.

\section{Introdução}

Com uma prolífica produção narrativa, María Rosa Lojo (Buenos Aires, 1954) vem ocupando um lugar de destaque no cenário literário argentino atual. Pertencente à geração dos filhos de exilados republicanos da Guerra Civil Espanhola (1936-1939), que migraram para a Argentina, sua construção identitária se deu no "entre-lugar" cultural. No ambiente familiar compartilhou dos desafios da adaptação, da resistência a novos elementos culturais e da aceitação de uma nova identidade,enfrentados pelos pais.

No ambiente domiciliar, conforme ressalta Lojo (2011, p.291), o desejo de regressar à terra natal (a Galiza de onde provinhaseu pai) foi possível apenas através da memória, muitas vezes apoiada na carga emotiva lançada sobre os objetos míticos. A conservação de fragmentos da cultura, história, memória e língua, ou seja, da identidade cultural, foi uma constante na tentativa de construir um lugar que preservasse e se prestasse a diminuir a

\footnotetext{
${ }^{1}$ Doutora em Letras pela Universidade Estadual Paulista (UNESP). Professora adjunta de literatura e língua espanhola na Universidade Federal de Rondônia (UNIR), no curso Letras espanhol. Rondônia, Brasil. E-mail: gracielle.marques@unir.br ib https://orcid.org/0000-0001-6342-5231
} 


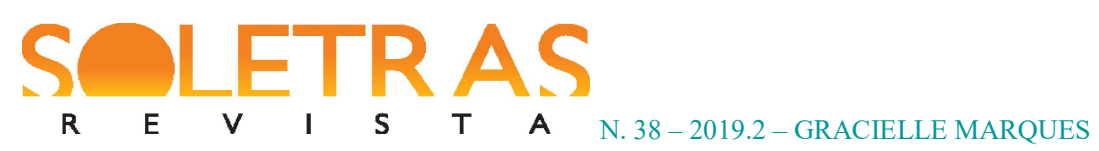

distância da pátria ausente entre os exilados republicanos (CRESPO BUITURÓN, 2008, p.46).

Desse modo, essa identidade cindida e residual transmitida à autora se reflete em sua produção artística, testemunha de seu íntimo esforço de criar, a partir das ausências, o mundo prévio a seu nascimento e transitar entre as culturas espanhola e argentina. Todas essas questões foram plasmadas em uma escrita híbrida e fronteiriça aberta às incertezas, às ambivalências, aos silêncios e, decididamente, singular. Com diferentes tonalidades, essa experiência entremeia tanto sua produção literária quanto sua produção ensaística. A partir de sua condição pessoal e familiar, que a escritora denomina de "exilada-filha", ela interpreta novas perspectivas formas e temas em sua poética,levando-nos a repensar sobre o pertencimento em face dos movimentos diaspóricos e o entrelaçar das experiências históricas e subjetivas.

Esse é o caso de sua produção microficcional, objeto deste estudo,na qual encontramos seus primeiros trabalhos. Visiones, seu livro de estreia, obteve o Primer Premio de la Feria Internacional del Libro de Buenos Aires em1984. Forma oculta del mundo foi publicado em 1991 após ganhar os prêmios de poesia Primer Premio Alfredo Roggiano e Segundo Premio Municipal de Poesía de Buenos Aires. Já em Esperan la mañana verde (1998) a escritora expressa sua potente capacidade de condensar mundos através de seu reconhecido fôlego de narradora e sua voz poética. Esse livro obteve uma maior projeção, já que foi traduzido ao inglês e ao francês.

Dentro dessa primeira fase de sua produção literária, menos estudada pela crítica, está seu segundo livro, Marginales (1986). Nele, Lojo desenvolve, sobretudo, o elemento narrativo, imiscuído de linguagem lírica, simbólica e reflexiva, tensionando os limites do conto breve. No ano seguinte, Canción Perdida em Buenos Aires al Oeste (1987) configura um passo em direção a sua exitosa e mais conhecida produção como romancista.

Nas narrativas da segunda fase, inaugurada com La pasión de los nómades (1994), a imprecisão genérica passa a ser sua marca distintiva. Lojo trabalha a matéria ficcional por meio da mistura deliberada dos gêneros memória, autobiografia, ensaio, poema, fantástico, romance histórico e conto. Nessas obras, a autora revisa a história argentina,questionandoos discursos nacionalistas que silenciaramoutras cosmovisões e uma parte significativa dos indivíduos que contribuíram com sua formação: os povos originários e as mulheres. 


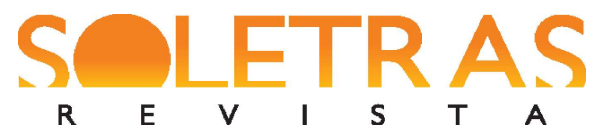

Tendo em vista esse breve resumo de sua biografia e de sua produção literária, nossa proposta neste estudo é analisar algumas das microficções que compõe o livro Bosque de Ojos: microficciones y otros textos breves (2011). Assim, refletiremos, primeiramente, sobre os possíveis sentidos dos deslocamentos genéricos que essas formas breves provocam. Em um segundo momento, analisaremos as microficções selecionadas, na ordem que foram publicadas em Bosque de Ojos, as quais versam os meandros da memória e do esquecimento vinculados à diáspora galega na Argentina. Nesse percurso, uma de nossas chaves de leitura é a da escrita breve como recriação da memória cindida do exilado. Para tanto, este trabalho conta com o embasamento teórico e crítico de Nicomedes Suárez-Araúz (2010), Francisca Noguerol Jiménez (2007), entre outros.

Em linhas gerais, Bosque de ojos se organiza em quatro partes e em uma ordem cronológica inversa a das publicações originais, isto é, começa pela mais recente, Historias del cielo (2010) e termina em Visiones (1984). O instigante título dessa compilação nos provoca um estranhamento devido à associação pouco comum entre os dois vocábulos. Mas, é possível perceber que ele se refere aos textos diminutos do livro e isso nos permita ver o imenso bosque de ficção em miniatura.

$\mathrm{Na}$ leitura das microficções topamos com uma grande quantidade de termos que se referem aos olhos e, de forma mais ampla, ao campo do ótico e do especular. O olhar, nesses fragmentos independentes, autônomos e proteicos, indica uma poética em constante movimento e mutação, na qual triunfa o perspectivismo; fixa-se na busca de uma realidade “outra", longínqua e transcendente. Além disso, não se trata de enfatizar o olhar cartesiano, da exterioridade e da superficialidade, predominante sobre os demais sentidos na nossa era, mas sim de um olhar corporificado, envolto e atravessado pelos demais sentidos. Essa percepção verticalizada é capaz de levar o leitor a um questionamentosignificativo sobre sua maneira de ver a realidade.

\section{Bosque de ojos: indeterminações e hibridação genérica}

O gênero da microficção ou minificção, nomenclaturas que adotaremos neste trabalho indistintamente, chama a atenção por sua abundante produção, qualidade estética e divulgação em diferentes meios durante as últimas décadas do século passado e início do século XXI, 


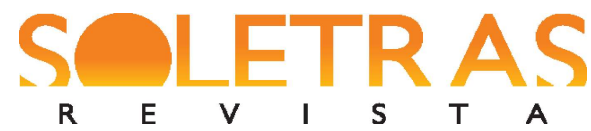

N. 38 - 2019.2 - GRACIELLE MARQUES

especialmente no âmbito da literatura hispânica. Os estudos críticos e teóricos sobre a microficção se intensificaram durante a década de 1980 e contaram com a contribuição de importantes estudiosos como Lauro Zavala (1996; 2006), Raúl Brasca (1996), Violeta Rojo, (1996; 2012), Francisca Noguerol Jiménez (2007), David Lagmanovich (2006), Laura Pollastri (2012), Fernando Valls (2008), entre outros.

Embora muito já se tenha escrito sobre os limites genéricos, especialmente os do microrrelato (microconto), e se pretenda fixar suas margens no elemento da narratividade, muitas minificções desbordam as caracterizações e disputam, com menos privilégios, a atenção dos leitores. Esse é justamente o caso de muitas das microficções de María Rosa Lojo que pouco se ajustam a etiqueta do poema em prosa.

As reflexões teórico-crítica sobre a microficçãovariam entre as classificatórias e restritivas e as que lançam um olhar abrangente sobre as formas breves para entendê-las em sua dinamicidade. A crítica à produção de textos breves lojiana não ignorou a problemática genérica. Dentre ela, destacamos o ensaio da professora e pesquisadora espanhola Francisca Noguerol Jiménez (2007), “Aguijones de luz: imagen y minificción em los textos breves de María Rosa Lojo", no qual posiciona os textos da autora dentro da tradição literária argentina de minificção. Seu texto oferece um panorama histórico dos cultivadores do gênero, que tem as figuras centrais de Jorge Luis Borges, Adolfo Bioy Casares e Júlio Cortázar, além de identificar algumas das filiações e afinidades textuais e artísticas das microficções lojianas. A partir dessa perspectiva, Noguerol Jiménez caracteriza Visiones e Formas Oculta do mundo como poemas em prosa e Esperan la mañana verde como minificção. A professora ainda ressalta o trabalho de criação imagética e simbólica de Lojo nesses textos breves.

Esse olhar crítico modificou a percepção que a própria autora tinha de seus textos, embora sempre fosse consciente de sua natureza fronteiriça, conforme revela:

Até alguns anos atrás, eu teria incluído esses textos (e de fato eu fiz) sob o título de "poemas em prosa", embora a "prosa" e a "dose de poesia" que essa prosa pudesse ter sempre ofereceram algum desconforto para os fãs das classificações. Quando apareceu a hospitaleira categoria de "mini" ou "microficção" essas incertezas ou dúvidas felizmente se diluíram (LOJO, 2011, p.247, tradução nossa). 
O peso conservador do sistema literário recusa obras que não se adequam a poética dominante da época, relegando-as às publicações modestas ou a outros sistemas literários (LEFEVERE, 2007, p.45), como foi o caso de Visiones e Forma oculta del mundo. Aparentemente, a compilação desses textos breves e sua vinculação a um gênero em voga mostram o trabalho da manipulação literária realizado pela autora para adequar-se às restrições do sistema. No entanto, ela reforça a resistência às categorizações oferecendo-nos textos breves de oscilante classificação.

As prescrições do gênero contrastam com a construção deliberada de uma voz própria fundada por um projeto estético ideológico fronteiriço e híbrido, ligado fortemente a sua biografia pessoal e familiar. Como afirma Lojo $(2011$, p.8) no prefácio de Historias Del cielo, mais do que simples jogo verbalsuas microficções anseiam abarcar outros estímulos presentes na criação artística, tais como o impacto que certas imagens podem provocar no leitor, a desautomatização do olhar, a intensidade sensorial, a experiência da irrupção, da concentração e da expansão de sentidos.

Com a clareza que lhe é própria, Lojo vai ao centro da questão sobre a condição básica definidora do microrrelato, isto é, a narratividade, em uma entrevista a Patricia Depetris (2004, p.193, tradução nossa):

[...] o que importa não é o desenvolvimento de uma peripécia, mas a fagulha, a fulguração, a explosão (que muitas vezes também é "subversão") semântica. Fico fascinada por essa indecisão: a narração que pode ser e nunca é completamente, porque se precipita, eclode, rebenta em pura poesia.

A escritora chama aqui a atenção para sua aposta na interação, indecisão, hibridação e tensão entre o poético e o narrativo. De certo modo, essa perspectiva espelha as tensões e ambivalências entre a memória/esquecimento coletiva familiar e a memória e os esquecimentos da sociedade argentina, atravessada por processos históricos recentes marcados pelo terror e pela morte.

Essas características indóceis às classificações, devido às porosidades entre as fronteiras dos gêneros textuais, entre outros entrecruzamentos artísticos, estão cada vez mais presentes nas manifestações literárias produzidas na América Latina na contemporaneidade. 


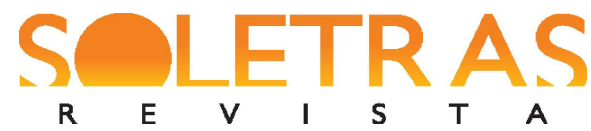

N. 38 - 2019.2-GRACIELLE MARQUES

Em um estudo sobre a inespecificidade na estética contemporânea, a argentina Florencia Garramuño (2014, p. 13) encontra na expressão "frutos estranhos” uma designação poética para as obras que colocam em questão as formas de pertencimento, em especial as formas breves que tensionam poesia e prosa. A estudiosa aponta ainda que essa insistência formal está unida às contingências da história recente de seu país, entre elas a imigração após a Segunda Guerra Mundial.

Nesse viés, passamos a examinar como esses textos breves plasmam as faces do exílio espanhol republicano a partir do que restou, do que se perdeu, do que não se pode capturar e do que, enfim, foi esquecido, mas atua de forma latente sobre a identidade pessoal e coletiva.

\section{O rastro dos dias sobre os objetos e a memória}

Diante da crise identitária provocada pela fragmentação da cultura, da memória e da história da diáspora galega, nos interessa questionar como e que estratégias estéticas são usadas para fabular o esquecimento. Assim, exploraremos as metáforas da dialética memória/esquecimento, as quais desenham um mundo cindido pelo exílio, cujos contornos rugosos se refletem na obra da escritora de modo autossimilar, mas em diferentes escalas, em uma aproximação com a geometria fractal.

Nesse ponto, é pertinente lembrarmos que a fractalidade tem sido apontada como um princípio concatenador de microficções seriadas. O crítico Lauro Zavala (2006, p. 48-49) estabeleceu esta ligação entre o conceito matemático de fractal e a estrutura seriada de certas composições microficcionais para explicar os textos que compartem os traços genéricos, estilísticos e temáticos, emrelação de dependência com a série a qual pertence.

$\mathrm{Na}$ teoria do caos, um fractal é uma entidade que reproduz sua forma em seu interior e dentro de uma escala cada vez menor. Assim, partindo da constatação de que as microficções de Lojo não foram escritas em forma de série integrada, conforme a proposta de Zavala, mas passaram a compor uma unidade graças à proposição da autora, percebemos, então, que os traços de união entre os microrrelatos ficam sugeridos ao leitor que, além de relacioná-los entre si, também pode perceber sua autossimilaridade com outros textos da produção lojiana. Essa possibilidade, também assinalada por Lojo em suas entrevistas, nos permite observar algumas microficções que se expandem em outros territórios artísticos da escritora. Isso nos 
leva a notaro fato de um texto passar a criar outro e uma parte poder representar o todo, semelhante aos fractais.

Um exemplo disso são as microficções "Ojo de Dios" e "Té de las cinco", publicadas em Esperan la mañana verde (1998), entre muitos outros casos, conforme indica a autora em algumas entrevistas. Nos casos citados, as temáticas funcionam como germens ou antecedentespoético-narrativos, posteriormente expandidos em outros textos. A primeira está no centro de El libro de las siniguales y el único sinigual (2016), no qual a busca incansável de Isolina pela totalidade é plasmada na descrição fantástica dos olhos de Deus. A segunda motiva a construção do conto "Té de araucária" (2011), no qual a autora explora a percepção das origensocultas nas pregas da memória por meio do paladar (MARQUES, 2019, p. 63). Disso depreendemos que, de certa forma, no universo literário próprio, construído por Lojo, todos os textos convergem. Com a aposta no multigênero, na integração entre poemas, contos, romances, ensaios e outros textos, as menores partes espelham o todo e atingem em cada ocasião uma nova configuração, porém sobre o mesmo território temático, ético e cultural.

Levando em consideração a perspectiva supracitada, estabelecemos o conceito do "objeto perdido" como objeto de investigação para nossa interpretação, com vistas a analisar o esquecimento/memória familiar e coletiva, desencadeados pelo movimento diaspórico republicano galego, presente nessas microficções de forma autossimilar no conjunto da obra da autora.

O conceito de "objeto perdido", delineado pelo poeta, ensaísta e artista plástico boliviano, Nicomedes Suárez-Araúz, em seu livro Amnesis Art: the Art of the Lost Object (1988), expressa esteticamente uma poética da ausência, fruto da amnésia. Esta se converte em um ato crítico e é eleita como a metáfora estrutural para a criatividade artística (visual, escrita e arquitetônica) do artista latino-americano, que deve confrontar-se com o esquecimento de nossa história primigênia. Para Suárez-Araúz, a amnésia é uma presença corrosiva que modela e refina nossas vidas. Longe de conotações negativas, ele entende a amnésia como o domínio do vazio, mas também da plenitude, do qual a criatividade artística e a fabulação se nutrem. Portanto, a memória é reavaliada como tão somente pequenos rastros imersos no invisível que contorna e rodeia a existência. Sua apreensão pela imaginação artística é elaborada esteticamente pelo princípio do "objeto perdido", conforme lemos nesta passagem: 


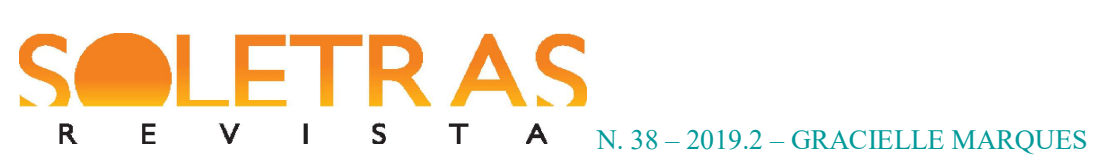

Os objetos descartados de nossas vidas irradiam com a incandescência de nossos seres internos. Nossa maior perda foram os incontáveis anos - não registrados na História Humana - que tateiam o infinito: um vasto espaço de imemorialidade ou amnésia. Este é o espaço que a arte alcança e onde nasce. Como tal, a amnésia incorpora o enigma da arte dos objetos perdidos. As obras desta arte são cartas ou mensagens para a amnésia. Elas são anjos, mensageiros que vibram com a ausência de coisas imersas no invisível. Essas criações nos trazem insinuações de objetos perdidos, corpos descartados e aquela fileira interminável de substâncias que chegam até o presente, formando e ecoando nossas presenças (SUÁREZ-ARAÚZ, 2010, p.42,tradução nossa).

Esse olhar poético parece inverter a direção da memória - tomada pelo empenho de tornar presente uma coisa ausente e o esquecimento como o "apagamento dos rastros e como falta de ajustamento da imagem presente à impressão deixada" - proposta por Paul Ricoeur (2007, p.27), para colocar o esquecimento no lugar de fonte criadora, de onde nos chegam substâncias que nos formam. Em outras palavras, na abordagem da memória no contexto latino-americano, não basta privilegiar o que ficou na superfície, mas o que se encontra submerso e ainda assim nos fortalece, delimita-nos e ressalta por contraste àquilo que conservamos, enquanto representação do que fomos e somos. A arte, portanto, é a tessitura criativa que reinventa os objetos e corpos descartados, comunicando os vazios que nos dão a forma eiluminando as descontinuidadesque estão na base da história latino-americana.

O caráter dialético e problemático da representação do passado (presença e ausência)atua de modo dinâmico e fictício sobre o sentido da identidade cultural, já que diante da amnésia reimaginamos e reinventamos a realidade.

Nesse prisma, na narrativa lojiana, a identidade é uma categoria conflitiva, pois a condição de "exilada filha" impôs o desafio de ser entre duas culturas. Os vazios deixados pelo deslocamento e os rastros da memória que desaparecem dentro de si mesmo seguem corroendo e, ao mesmo tempo, dando espessura a uma identidade desdobrada.

Diante da cisão com o lugar e as práticas sociais de origem, com as quais nossas identidades se encontram estreitamente ligadas (HALL, 2014, p.41), narrar ou visionar se oferece como vias para questionar as ausências, as desaparições e encontrar o significado, a trama das contingências da vida. 


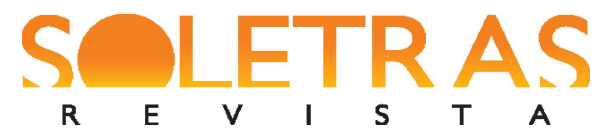

Então, passemos ao exame dessas proposições na tessitura de algumas microficções, com especial atenção para as de Historias Del cielo e Esperan la mañana verde.

\section{Historias Del cielo}

Nesse livro somos convidados a refletir com desconcerto e admiração os paradoxos da eternidade. A travessia do Lete, rio do esquecimento, que separava o mundo dos vivos e o mundo dos mortos na mitologia greco-latina, reinventa o silêncio, as perdas, as injustiças e as ausências; realça as construções da memória, em muitos casos invisibilizadas pelos discursos dominantes. A viagem ao reino da eternidade desafia as proibições do olhar, não do olhar sobre o outro mundo, mas sobre nós mesmos.Inesperadas associações e inversões de perspectiva configuram alguns dos procedimentos chaves desse livro.

Em "Objetos perdidos", por exemplo, podemos destacar a relação entreesquecimento e memória na construção fragmentária da identidade:

Sobre mesas inesperadas, en cajones imposibles, sin mueble en que encajar, sólo sostenidos por el aire, los que fueron niñas y niños hace mucho podrán encontrar en el Cielo sus destruidas y acaso nunca olvidadas pertenencias: una muñeca de porcelana con la cabeza rota, la campanilla del trineo Rosebud; una pelota de trapo aplastada por un carro, un trompo sin colores, un muñeco a pilas, oxidado, con el inútil brazo en alto para tocar un tambor ya inexistente.

Acaso Dios los mirará jugar con esos despojos, ávidos y desconcertados, arqueólogos de sí mismos que intentan reconstruir con fragmentos de fósiles el esqueleto de una vida remota (LOJO, 2011, p.24).

"Um objeto encontrado pode nos surpreender com as qualidades que ele manifesta; um objeto perdido nos angustia com o brilho de sua ausência”, reflete Suárez-Araúz (2010, p.42. tradução nossa). Os objetos da microficção aludem à ausência corrosiva, que ocupa o vasto espaço do tempo imemorial, contra o qual nos confrontamos com a imaginação; são o elo que nos permite conectarmos novamente com todas as idades, especialmente a infância. $\mathrm{O}$ que importa nesses objetos não é seu estado de conservação, mas sim o potencial de atuarem na reconstituição de vivências e experiências passadas, dando novos enleios ao sentido de 


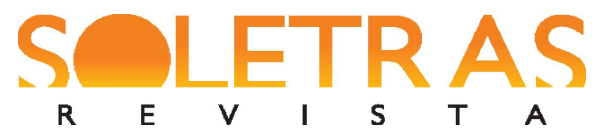

identidade. A dialética do objeto perdido e encontrado suariano emerge da vastidão da eternidade e adentra o espaço a-histórico em busca dos fragmentos necessários para a narração pessoal.

Fica evidente que a reconstituição da identidade pessoal é sempre parcial, pois o acesso a sua totalidade é negado, sendo concedida somente a possibilidade de narrar a si próprio a partir de uma seleção de fragmentos e pedaços incompletos. Daí que, nesse texto, aparece um elemento marcante da escrita de Lojo, ou seja, a desestabilização das certezas. O que há são condições para o hipotético ("acaso nunca olvidados", "Acaso Dios"), pois os objetos são tão precários quanto os móveis que poderiam abrigá-los ("Sobre mesas inesperadas, em cajones imposibles"), isto é, os mecanismos que os sustentam, correlatas divisões que abrigam nossas memórias.

A carga identitária dos objetos perdidos lojeanos são os disparadores da memória afetiva, conforme lemos no singular "Los três días" (LOJO, 2011, p.45), da mesma seção. Assim como na microficção anterior, cria-se o paradigma imaginativo da memória da infância, o qual representa o sentimento máximo de perda. "Los três días" narra o sucedido nos três dias após a morte de Cristo, quando este perambulou pela terra antes da ascensão. Cristo, convertido em um desterrado, retorna a casa materna e dirige-se ao quintal, onde encontra os objetos perdidos, que povoaram sua infância e que dão sentido a sua existência terrena. A personagem de Cristo reconhece a dor da perda, da irremediável distância que nos separa do passado. Sentado à beira do poço, seu profundo desconsolo reflete sua condição fronteiriça. Nisso se vê o drama do primeiro homem, Adão, expulso do paraíso, impedido de retornar, em uma situação análoga a do exilado republicano. O relato, no entanto, não é nostálgico, no sentido de o tempo passado ser exaltado em detrimento do momento presente.

O sentimento de extravio é insistentemente evocado por Lojo por meio dos fragmentos do cotidiano. Eles ecoam a presença de nosso habitar terrestre, rompendo o silêncio que envolve todas as coisas quando as perdemos, conforme lemos nos textos a seguir.

\section{Esperan la mañana verde}

Nesse livro, a vida, aparentemente ordinária, é atravessada por aquilo que estava oculto ou à espreita no inconsciente, isto é, os objetos perdidos, emblemas da amnésia. As 


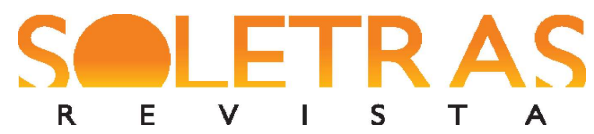

N. 38 - 2019.2 - GRACIELLE MARQUES

coisas e seres participam, com matizes lúdicos, fantástico e transcendente, da reconstrução de uma realidade metamorfoseada, poética, onírica e aberta.

O ambiente da casa e os vínculos com o doméstico se sobressaem nesse livro. Tradicionalmente ligada ao conhecido e ao delimitado, a casa é o lugar no qual a memória encontra suas raízes, mas quando cruzada pelo tempo reforça as relações com os ausentes (HALL, 2014, p.41). No desterro a casa é o lugar onde se recarregam os sentidos de um mundo ausente, onde se (re)tece a subjetividade mediante certas ausências, silêncios e rastros. É o que podemos ler na microficção “Transparencia” (LOJO, 2011, p.76).

O texto focaliza uma transformação ocorrida à personagem feminina dentro de uma situação mínima em termos de fábula a qual, no entanto, adquire um releve surpreendente. A primeira frase nos oferece uma moldura narrativa: a ação reiterada de uma mulher que se senta no quintal de sua casa a cada entardecer. Em seguida, nos é descrita a transformação cotidiana: a insólita luminescência de seu corpo à medida que ela canta e a noite avança. Os elementos "atardecederes" e "patio de la casa", podem ser lidos de modo simbólico como o tempo-espaço, no qual o ritual da revelação de memórias passadas se manifesta em seu corpo, eixo de diferentes mundos. Mediante enunciados que expõem as ações de forma sequencial somos convidados a penetrar em uma segunda realidade, cuja porta de entrada está na última ação realizada pela mulher: ela guarda a cadeira e retorna à cozinha levando consigo o segredo da transparência.

O gesto da mulher que canta no quintal a cada entardecer - momento de contraste, no qual a consciência se dá - é um acontecimento poético voltado para dentro e banhado de luz (transparente, encendido, resplandor, iluminado, transparencia). Quando pensamos que esse acontecimento arrastaria a personagem para o mundo das reminiscências ela volta a sua opacidade, guarda a cadeira, encerrando o ritual. O resplendor do esquecimento sobrevive subterrâneo quando a mulher volta ao ambiente privado (lacocina), que marca tradicionalmente a posição e a ordem do corpo na sociedade patriarcal. Deste modo, o delinear de outra realidade emoldurada pelo multissensorial é desvelado por uma poderosa lente que capta uma dimensão oculta e nos exige a atitude da visão.

A canção pode ser lida com o sentido assignado ao "objeto perdido" suariano. Ela é um importe símbolo lojeano, na maioria das vezes ligada ao universo feminino, ese associa ao sentimento de perda do sujeito deslocado, exilado ou do imigrante, transmissor da história ancestral de modo individual e coletivo (CRESPO BUITURÓN, 2008, p.151). O canto é um 


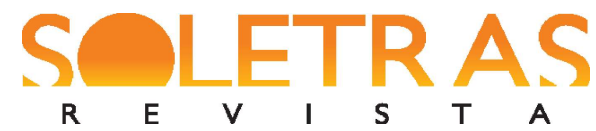

N. $38-2019.2$ - GRACIELLE MARQUES

gesto performático que nos obriga a ver e a ouvir as vozes suplantadas pelos dispositivos de poder da cultura letrada.

Em "Ciertas herencias" (LOJO, 2011, p.77), microficção que segue a anterior, podemos observar a continuidade dessa representação, a qual reflete a experiência do exílio, da memória, das emoções suscitadas pelas ausências, que passam às gerações posteriores como pertences, através dos objetos domésticos mensageiros da presença espanhola. Os objetos inanimados das avós da voz narrativa são uma das vias de recuperação da memória familiar. A almohada de terciopelo, a trenza roja e um mantón de Manila são fragmentos de um passado que recobram vida através da imaginação da neta. Nesse texto, encontramos um dos temas típicos da literatura fantástica, o "animismo de objetos", que, nesse texto, é habilmente incorporado à rotina diária. $\mathrm{O}$ deslizamento da realidade por meio desses objetos perdidos, pertencentes a um passado submerso dentro da própria neta, não apenas ativa a memória afetiva distante, mas principalmente revela um olhar apurado e sensível de umaausência presenteque serve de libertação para a personagem.

Essa mesma ideia está replicada em "Estructuras de la casa". Sem perder sua funcionalidade, um dedal, uma foto, uma luva, uns pratos, um cofre ou uma carta podem adquirir outra relação com o sujeito. Ultrapassam os limites de sua materialidade e se entrelaçam em uma rede de imagens que cria um mundo dentro do outro, em uma série de histórias infinitas. Nesse texto, por meio dos objetos domésticos forma-se o inventário das desesperanças, do sentimento de estar fora do lugar experienciado pelos exilados, da pátria ou de si mesmo. Um exemplo disso são as cartas: "dentro de un cofre la madre guardaba cartas de pretendientes, y con las cartas esperanzas y pobrezas que avanzaban despacio sobre el papel rugoso de las vidas pasadas" (LOJO, 2011, p.105). O desvanecimento do tempo atua da mesma forma sobre as expectativas da mãe. As cartas guardam seu valor emocional, mas o sentido da esperança em uma vida diferente é corroído, permanecendo apenas enquanto contorno das perdas.

A percepção do oculto nas dobras da memória é desencadeada pelo paladar, em "Té de las cinco" (LOJO, 2011, p. 91), do mesmo livro, que merece ser transcrito in extenso:

Una taza de té con sus hojas dispersas en el fondo: hay allí un ojo extraviado, hay una boca que no halló la palabra, hay una pierna atravesada en medio del camino, hay una mano que no sabe coser. Hay un 


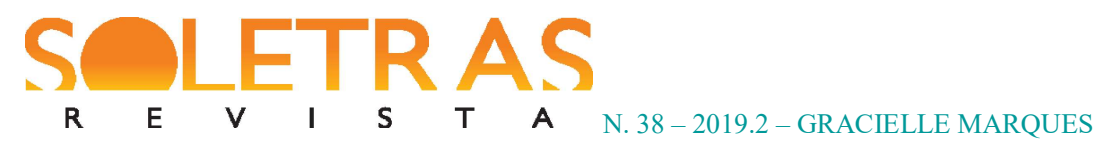

mapa secreto de una ciudad ya inhabitable donde viviste. Hay un llamado inaudible, hay una música que podría volverte el alma del revés, si la escucharas.

O tradicional ritual do chá das cinco inglês, título dessa microficção, sugere a existência de uma memória oculta nos interstícios do cotidiano, de outras vozes identitárias estranguladas por uma narrativa dominante. A última oração (“si la escucharas") dá o sentido a todo o texto precedente e ressalta a impossibilidade de se ouvir o chamado, a mensagem secreta e a canção, metáforas da narração de contra-memórias. Porém, o grupo sintático encabeçado pela anáfora "Hayun" confronta a ameaça do silêncio que remata o texto.

O tom poético que reveste o texto também corrobora a ideia de que o anedótico não pode emergir de maneira transparente e completa. As referências metonímicas das partes do corpo insistem na dispersão das referências familiares e culturais sofrida na condição de exilado. Por fim, adistância entre um "aqui", onde repousa a xícara de chá e um "lá", toma a forma do esquecimento. É o espaço que as palavras não podem alcançar, alimenta, entre outros aspectos, essa visão fragmentada e fronteiriça da realidade que Lojo aspira cifrar.

$\mathrm{O}$ esquecimento pessoal reverbera o esquecimento coletivo, conforme observamos ao visitar o museu noturno em "Museos de palacio" (LOJO, 2011, p.122). Durante o dia a coleção de objetos museológicos, disposta em uma ordem didática, está ao alcance da anêmica interpretação dos turistas (Recogen los fragmentos de un mundo inmóvil y obediente, puesto en orden didáctico). O gesto dos guardas proibindo as fotografias para manter a conservação dos "restos" é ironizado pela constatação da finitude dos objetos, assim como a dos esquecidos artesãos que as elaboram.

A amnésia que envolve o reconhecimento do trabalho dos artesãos anônimos, ocultos sob a assinatura de seus mestres (autoridade), é deslocada. Nessa ocasião, Lojo introduz o elemento fantástico que transgride a ordem estática e adentra o a-histórico, o vazio da memória. Os artesãos retomam suas atividades e voltam ao museu à noite para transformar a sala morta em um movimentado ateliê. O museu noturno nasce do esquecimento e do poder imaginativo que ele inspira. As tensões duais entre dia/noite, vida/morte, imobilidade/ação, latência/revelação e história/memória são o modo de ilustrar o implícito processo de apagamento de identidades culturais minoritárias, operado pelas construções homogeneizadoras. O lado noturno, amnésico e perdido, cria essa atmosfera estética de que 


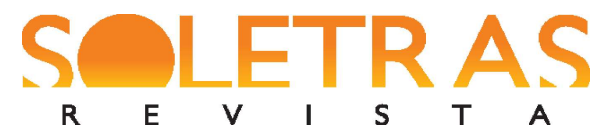

fala Suárez-Araúz (2010, p.26) em seu "Manifiesto Amnesis", pois provoca a desassociação da acomodação didática e da continuidade histórica e, especialmente, nos conduz a uma capacidade interpretativa dos signos que vai além do tangível e do recuperável.

\section{Forma oculta del mundo}

Nesse livro, a necessidade de contar se esmaece, embora se insinue em muitos textos, e o poético toma o terreno para circundar outras percepções, conforme um dos textos afirma: "no hay tema fijado, hayun constante rodear lo que se escapa" (LOJO, 2011, p.168). O processo associativo da criação poética se alinha à "tendência de nossas mentes a inventar ou enfrentar o esquecimento" (SUÁREZ-ARAÚZ, 2010, p. 175, tradução nossa). O tom quase lírico dessas microficções alcança falar do que se desprende e se perde; daquilo que da espessura ao secreto e ao oculto da realidade, do que se concentra no centro do todo e não pode ser alcançado, enfim, daquilo que não podemos recordar, conforme alude o próprio título.

Nesse contexto, o tema do exílio ganha outras perspectivas. A ideia de retorno às origens e ao "mundo ausente" reflete o sentimento de transitoriedade e desajuste herdado dos pais no exílio republicano e são elaborados em vários desses textos breves na forma de uma memória imaginada, inventada ao redor de objetos míticos. Formam uma rede significativa com o universo feminino da costura e da fiação, como podemos destacar em outras microficções de Bosque de Ojos como, por exemplo, em "Órdenes" (2011, p.93), "Tejidos" (2011, p.99), "Hilando con los rayos de la luna" (2011, p.156) e "Cualidades del invierno" (2011, p.106), entre outras.

Se esses objetos míticos (roca, fuso, fotografia, cartas, tecidos, etc...) estão fortemente associados a casa e sua simbologia, também estabelecem relação com o espaço externo e aberto que nos remete de modo metonímico ao espaço geográfico da Argentina e da Galiza paterna (jardim, planície, casa de pedra, bosque, mar, lobo e todo um imaginário vegetal), como podemos ler em "Este bosque" (2011, p.69), "Siempre Galiza" (2011, p. 118), “Finisterra, A.C" (2011, p.119), “Revelaciones, III" (2011, p.227) e "Los avatares, II" (2011, p. 232), entre muitos outras microficções narrativas e líricas. 


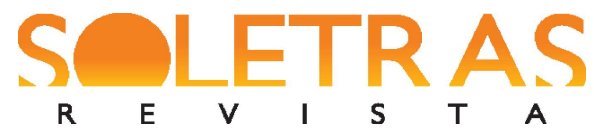

Em "Retorno" (LOJO, 2011, p.173) da sessão "Tránsitos", de Formas oculta del mundo, podemos observar a manifestação do espaço construído e a luta contra o esquecimento, em um gestode resistência cultural:

Has visitado la casa permanente, la más extrema de la primavera, la verdeoscura, con su amparo de hiedras, la que cela con el pudor del bosque el encarnado ladrillo y las bárbaras piedras ascendidas. Te han invitado a la mesa más honrosa, con los ancianos. Has bebido los vinos añejos y las copas cuya edad nadie cuenta se ofrecen para ti con su callada lozanía de espejos. Has revisado retratos de familia, los rostros públicos y aun las cartas secretas. Te has confortado al amor del hogar frío y las últimas brisas violentas te han perseguido con su arrasado aliento de azahares: a ti, viajero, que desde el extremo detenido del tiempo vuelves a tu casa mortal, a tu casa fugaz, tácito y ebrio.

Na edição de 1991, o título "Viajero" ressalta a errância do viajante. A importância da mudança demonstra a opção da autora por introduzir uma interpretação relacionada com a noção de movimento reiterado, isto é, o retorno à casa anelado pelo imigrante ou simbolicamente a busca espiritual por um centro original. Dessa forma, o título destaca a ação principal do "tu” (viajante), personagem que atua no nível da fábula: é quem realiza o duplo retorno à casa de pedra (das origens míticas) e à casa mortal.

Enunciado por um "eu poemático", o viajante retorna a casa mortal depois de ter estado na antiga casa, espaço interior relido e construído. Na casa, os antigos moradores recebem o viajante para partilhar novamente dos rituais, de objetos pessoais e dos segredos familiares. A casa de pedra é uma reação imaginativa; uma forma reconfortante de reconstruir aquele sentido íntimo e secreto do mundo perdido. As ações são expressas significativamente no pretérito perfeito composto, tempo verbal da língua espanhola, pouco usado na variante rio-plantense, que indica ações passadas dentro de um marco temporal presente, reforçando a noção de que o presente do "eu poemático"contém seu passado. Na sequência, é anunciado o retorno por meio de uma afirmação no presente (vuelves a tu casa mortal), o que situa a ação realizada na casa de pedra, possivelmente, em um ambiente onírico. Esse outro retorno é, no entanto, para um lugar mortal e fugaz. Tal disjunção entre a casa de pedra e a casa mortal é acentuada com os semas do silêncio e da embriaguez que envolve o viajante, o qual só pôde 


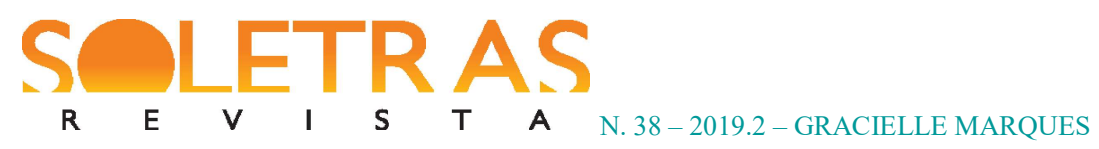

reter alguns fragmentos do mundo sonhado, pois todo o mais está submergido no esquecimento.

\section{Visiones}

Esse é o livro com o menor número de textos, vinte e dois textos. Porém, nele encontramos um verdadeiro "bosque de imagens". As subdivisões desse livro são precedidas por epígrafes, com os quais podemos tentar clarificar aquilo que não pode ser iluminado, senão pelos caminhos ambivalentes das próprias citações, indícios da configuração do bosque de referências literárias da autora. Nessas criações, um "eu" ou um "tu" lírico caminham por um reino transitório, em guerra, acessível apenas através da memória e captado em um estado de sonho, pesadelo, insônia, alucinação e outras dilatações da visão. Tudo toma uma voltagem poética. As construções sinestésicas, oníricas e simbólicas provam o interesse e a imaginação do leitor. Nas palavras de Silvia Sauter (2007, p. 106, tradução nossa), formam "uma realidade que permite vislumbrar outras dimensões ou possibilidades de conhecimentos".

A forte predominância simbólica e alegórica nos livros Forma oculta del mundo e Visiones, encalçada pela linguagem onírica, isto é, pela suspensão artística da lógica e da coerência serve de estratégia amnésica, em referência à estética suariana, para entrar no ahistórico, nos vazios mnemônicos ou, ao menos, nos convolutos planos temporais e espaciais (SUÁREZ-ARAÚZ, 2010). Pode-se entender esse procedimento associando-o a busca por umarepresentação do real como experiência incoerente, contraditória e dilacerada. $\mathrm{O}$ resultado, de forma geral, indica a conjunção de duas dimensões, individual e coletiva, que são atravessadas pelos impasses políticos do momento e pela experiência subjetiva de reelaboração do desajuste cultural. A incidência dessa construção pode ser lida na microficção II da sessão “La palabra muda” (LOJO, 2011, p.220).

Trata-se de um texto gerado a partir da perspectiva do que ocorre nos arredores ou no interior dos sonhos. A exploração da matéria onírica sobrepõe imagens que parecem querer organizar-se de forma narrativa, mas que se verticaliza tocando sentidos mais profundos que uma simples peripécia. Nos dois primeiros parágrafos, somos remetidos ao ambiente escolar. Através do ritual inaugural de cantar o hino pátrio diante da bandeira é transmitido o valor da pátria. Esse gesto pretende uniformizar o sentimento e a função de cada ser que está sendo 
preparado para um combate em defesa da pátria ("Siendo diversos nos vemos forzados a la igualdad momentanea, al uniforme sonido redondo"). Na sequência, as portas físicas se abrem e um "microclima" de odores acres faz a visionária associá-los com os odores de uma guerra.

No terceiro parágrafo, a visão desse combate externo assinala um combate interno. Nesse ponto é interessante estabelecermos uma leitura paralela com o romance Todos éramos hijos (2014), protagonizado por Frick, alter ego da autora. A narrativa se inicia com a descrição do primeiro dia de aula, caracterizado pelo mesmo ritual patriótico, e o sentimento de inadequação e insegurança revelado pela narradora-personagem. Ao longo desse romance, a questão identitária toma espessura no desdobramento da adolescente Frick entre a cultura espanhola transmitida em casa e a cultura argentina do ambiente escolar. O pano de fundo do relato é a década de 1970, período de maior violência e terror da ditatura militar. A essa altura, a personagem completa seus quinze anos e passa por um momento de profundo desolamento, ao mesmo tempo em que experiência o autoconhecimento. Em um dos seus momentos de combate ela se alojava no quarto nos fundos da casa, onde convergiam todos os jardins e pátios, e a hora crepuscular, como na microficção "Transparencias", recebia as visões das caravanas, que cruzavam o rio do esquecimento buscando instalar-se na memória eterna de Deus.

A defesa de sua vida se dará por meio das palavras, ou seja, de seu interesse pela literatura. $\mathrm{Na}$ microficção as situações conflitivas do período escolar são apresentadas na visão. No entanto, o texto não se encerra com o fim da visão, ou melhor, a visão não se encerra com o seu fim, pois segue afetando a visionária:

Transcurre el plazo de la visión; los combatentes inquietan aquellas aguas lúcidas; los cascos de caballos, los campamentos y las naves ancladas. Todo asedia tu centro. Atacarás también. Es necesario (LOJO, 2011, p.220).

O que assalta a tranquilidade da visionária são as imagens desse ambiente onírico; são esses fragmentos bélicos (los cascos de caballos, los campamentos y las naves ancladas) que subiram do sonho e ali permanecem, à superfície do mundo real. A resposta é imediata, 


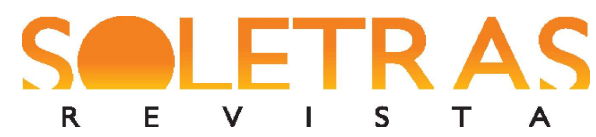

N. 38 - 2019.2 - GRACIELLE MARQUES

poética, aberta ao universo multiplicador de sentidos; contrária à opressão da visão e as silhuetas do pesadelo eminente da vigília.

\section{Considerações finais}

O fato de Lojo cruzar permanentemente os limites dos gêneros literários quebra com certa expectativa por parte da crítica de tentar classificar sua produção. Quando lemos sua ampla produção literária para além das delimitações do gênero ou das classificações que se queira efetuar, podemos perceber como certas hesitações e visões reverberam no texto como espaço crítico, marcado por uma necessidade de questionamento do próprio, do específico, da identidade e do pertencimento. Como em toda boa literatura, forma e conteúdo se encontram profundamente imbricadas em uma amostra clara de que os textos devem ser lidos em todas as suas dimensões de sentido.

Os recursos, procedimentos e peculiaridades estruturais presentes na microficção, entre eles a elipse, o final aberto eadiluição de elementos narrativos e líricos, são combinados com maestria por Lojo para tratar de um tema que lhe é particularmente caro.

O acúmulo dos fragmentos que formam o Bosque de ojos está implicado na tarefa de ressignificar o "entre-lugar" cultural enraizado em sua biografia pessoal e familiar, que padece do sentido de totalidade. Dessa forma, a habilidosa indecisão entre revelar, narrar, ocultar e sugerir necessária à formulação exitosa desse tipo de composição enriquece a dialética memória/esquecimento sob o ângulo do "objeto perdido" suariano, expressão simbólica do esquecimento, das ausências, distâncias e vazios que funciona como matéria criativa para reinventar a própria identidade, feita de lacunas. É a fonte da qual brotam pequenos detalhes, mensageiros das origens, do oculto e palpitante dentro de nós.

Embora as microficções de Lojo sejam miniaturas autônomas, é possível, conforme sugere o título do volume, realizar leituras que conjugue outros traços estilísticos e temáticos sobressalentes, como o esquecimento. Assim, com diferentes perspectivas as microficções analisadasapresentam, na maioria dos casos, elementos simbólicos em comum: a infância, a casa, o bosque e os objetos domésticos emblemáticos de um mundo esquecido que atua sobre a memória. Esse microcosmo é a pátria dos exilados e seus filhos, por meio da qual preservam as marcas de sua identidade. Algumas das composições coincidem em recriar um ato ritual, 
além de símbolos que ambiguamente realizam a união dos planos físico e metafísico. No entanto, essa tentativa está permeada de impedimentos, de condições hipotéticas e de imperceptíveis e paradoxais conexões, pelas quais a memória adquire realidade social e sentido cultural.

Os objetos domésticos não são apenas o que aparentam ser, mas signos diversos. Eles reavivam afetos, criam um espaço imaginado e imaterial se imiscui no real criando uma recordação que torna visível a desorientação espacial, o desprendimento do outro vivido como um sentimento de perda e incerteza. Esses relâmpagos narrativos e poéticos servem de contraste para uma vida mergulhada na opacidade, na marginalização, no esquecimento, pois o que importa é o que pode ser visto e imaginado por detrás da história, do cotidiano, da memória.

Conforme enfatizamos, os livros de Bosque de ojos caminham em direção a um adensamento da realidade, da qual emergem as visões oníricasque devolve um modo de ser e existir no limiar. A visão cartesiana, de espectador externo conjuga-se com a percepção interior mostrando-nos nossa indissolúvel relação com o mundo. Os olhos convidam outras modalidades sensoriais e a linguagem poética encaminha o ser ao centro do mundo interior.O esgarçamento dos limites em âmbitos diversos (o sonho, a eternidade e o passado), explora as contradições da realidade temporal e espaciais fragmentarias, distante e imemorial, sob o signo da iminência, da dissolução, da incongruência e de espicaçadas imagens de pesadelos bélicos.

Por fim, a experiência com a leitura dessas formas breves se vê particularmente tocada pela atitude participativa, não apenas para reconstruir e completaro que é contado ou apenas sugerido pelo texto, mas, sobretudo pelo prazer estético da reconstrução pelo esforço interpretativo desse universo diverso e uno ao mesmo tempo.

\section{Referências}

CRESPO BUITURÓN, Marcela. Andar por los bordes. Entre la historia y la ficción: el exilio sin protagonistas de María Rosa Lojo. Tese (Doutorado em Letras) Facultad de Letras de la Universidad de Lleida, Lleida, 2008. Disponível em: $<$ http://www.cervantesvirtual.com/obra/ andar-por-los-bordes-entre-la-historia-y-la-ficcion-el-exilio-sin-protagonistas-de-maria-rosalojo--0/>.Acesso em: 20 jan. 2018. 


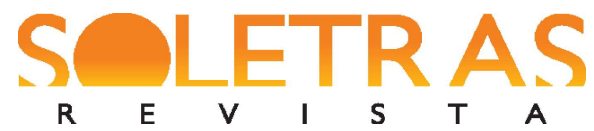

N. 38 - 2019.2 - GRACIELLE MARQUES

DEPETRIS, Carolina. La inexorable tentativa de la poesía: preguntas a María Rosa Lojo, RILCE, 2004, XX.2, p.191-198.

GARRAMUÑO, Florencia. Frutos estranhos: sobre a inespecificidade na estética contemporânea. Trad. Carlos Nougué. Rio de Janeiro: Rocco, 2014.

HALL, Stuart. A identidade cultural na pós-modernidade. Trad. Tomaz Tadeu da Silva e Guacira Lopes Louro. Rio de Janeiro: Lamparina, 2014.

LEFEVERE, André. Tradução reescrita e manipulação da fama literária. Trad. Claudia Matos Seligmann. Bauru, SP: Edusc, 2007.

LOJO, María Rosa. Bosque de ojos: microficciones y otros textos breves. Buenos Aires: Sudamericana, 2011.

Entrevista concedida a Mónica Prandi, [online]. Disponível em:

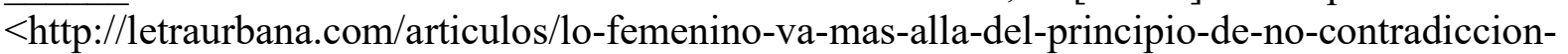
entrevista-a-maria-rosa-lojo/> Acesso em: 03 mar. 2019.

"Fronteiras, finisterras e corredores: do clichê ideológico polissemia simbólica". Trad. Antonio Roberto Esteves. In: PINTO, A.; MACHADO, M. \& VILALVA, W. (orgs.). Nas dobras do mundo a literatura acontece. São Paulo: Arte e Ciência, 2011.p.287-315.

. Todos éramos hijos. Buenos Aires: Sudamericana, 2014.

MARQUES, Gracielle. Rumores, sombras y silencios: lo oculto manifestado en las narrativas de María Rosa Lojo. Gramma, Buenos Aires, ano XXX, n.62, p.59-75, 2019. Disponível em $<$ https://p3.usal.edu.ar/index.php/gramma/article/view/4679/5982> Acesso em: 30agosto. 2019.

NOGUEROL JIMÉNEZ, Francisca. "Aguijones de luz: imagen y ritmo en los textos breves de María Rosa Lojo". In: ARANCIBIA, Juana A., FILER, Malva A. y TEZANOS-PINTO, Rosa. (eds.). María Rosa Lojo: la reunión de lejanías. Buenos Aires: ILCH, 2007.p.79-95.

RICOEUR, Paul. A memoria, a história, o esquecimento. Trad. Alain François et al. Campinas: Editora da Unicamp, 2007.

SAUTER, Silvia. María Rosa Lojo: escrita visionaria. In: ARANCIBIA, Juana A., FILER, Malva A. y TEZANOS-PINTO, Rosa. (eds.). María Rosa Lojo: la reunión de lejanías. Buenos Aires: ILCH, p.97-110, 2007.

SUÁREZ-ARAÚZ, Nicomedes. Amnesis: The Art of the Lost Object. Nova Iorque: Lascaux Publishers, 1988.

Loén: un mundo amazónico olvidado. Antología de la obra loeniana y la estética de la Amnesis. La hoguera: Santa Cruz de la Sierra, 2010. 


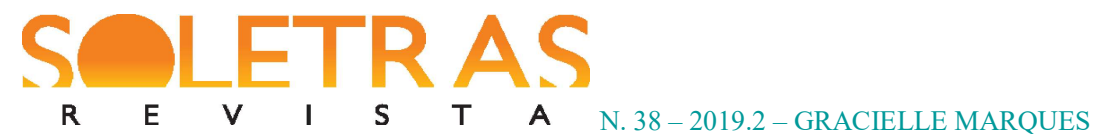

ZAVALA, Lauro. Fragmentos, fractales y fronteras: Género y lectura en las series de narrativa breve. In: BRESCIA, Pablo; ROMANO, Evelia (coord.). El ojo en el caleidoscopio. México, DF: Universidad Nacional Autónoma de México, 2006, p.35-52.

\title{
Poetics of forgetfulness: an approach to the microfiction of María Rosa Lojo
}

\begin{abstract}
This paper focuses on the analysis of some microfictions in the book Bosque de Ojos: microficciones y otros textos breves (2011), by María Rosa Lojo (1954 - Buenos Aires). Produced over more than two decades of work, the lojians microfictions form a set marked by generic hybridity, reinforcing the multifaceted character of his literary project. Many of these brief forms share generic and thematic traits that reconfigure the notion "of in-between place" of their "exile-daughter" condition in a unique way. From the "lost object" concept of Suárez-Araúz (2010) and the critical studies on the microfiction of Noguerol Jiménez (2007), Zavala (2006), among others, this analysis aimed to establish the relation between brevity and recreating the split memory, a reflection of the Galician diaspora. As the result of the analysis, in broad outline it is possible to ascertain Lojo enriches the dialectic memory / forgetfulness under the angle of lost objects, a symbolic expression that works as a creative material to reinvent cultural identity, made up of gaps.
\end{abstract}

Keywords: Contemporary Argentine literature. Exile. Lost object. Microfiction.

Recebido em: 31 de maio de 2019.

Aceito em: 03 de setembro de 2019. 